\title{
Determination of 1-Naphthol Concentration on Electrode Modified with Electrochemically Polymerized $\beta$-Cyclodextrin Film
}

\author{
Zhaorong Liu, ${ }^{1}$ Yuchun Wang, ${ }^{1 *}$ and Chao Tan ${ }^{2}$ \\ ${ }^{1}$ Department of Applied Chemistry, Yuncheng University, Yuncheng, Shanxi 044000, China \\ ${ }^{2}$ Key Lab of Process Analysis and Control of Sichuan Universities, Yibin University, \\ Yibin, Sichuan 644000, China
}

(Received March 18, 2020; accepted August 11, 2020)

Keywords: $\quad \beta$-cyclodextrin-film-modified electrode, 1-naphthol, cyclic voltammetry, AC impedance

A glassy carbon electrode (GCE) modified with poly $\beta$-cyclodextrin $(\beta-C D)$ film $(\beta-\mathrm{CD} / \mathrm{GCE})$ was prepared. The electrochemical properties of the $\beta-\mathrm{CD} / \mathrm{GCE}$ were explored by cyclic voltammetry $(\mathrm{CV})$ and $\mathrm{AC}$ impedance measurement, and the obtained results indicate significant improvements in impedance and electrocatalysis behavior. Further experimental results show that in $\mathrm{HAc}-\mathrm{NH}_{4} \mathrm{Ac}$ solution ( $\mathrm{pH}$ 5.55), the electrocatalysis of 1-naphthol is very clear on the polymerized $\beta-\mathrm{CD} / \mathrm{GCE}$. The peak current increased linearly with the concentration of 1-naphthol in the range of $2.05 \times 10^{-3}-1.07 \times 10^{-6} \mathrm{~mol} \cdot \mathrm{L}^{-1}$, and the detection limit was $3.06 \times 10^{-7} \mathrm{~mol} \cdot \mathrm{L}^{-1}$ at an SNR of 3:1. The modified electrode was applied, with satisfactory results, to the determination of 1-naphthol concentration in tap water, and its recovery rate was between 97.3 and $103 \%$.

\section{Introduction}

1-Naphthol, which is used as the raw material of the insecticide Sevin, is now in great demand. It is a large-scale industrial chemical that is widely used in the manufacture of dyes and insecticides, and is also a secondary product of chemical, paint, paper, and pesticide industries. In addition, it is a kind of phenolic compound with high toxicity and thus has a profound effect on the environment and health of people. ${ }^{(1-3)}$ Currently, the common methods of determining the concentration of 1-naphthol include high-performance liquid chromatography (HPLC), ${ }^{(4-6)}$ the use of quartz crystal microbalance (QCM), ${ }^{(7)}$ immune cytochemistry, ${ }^{(8)}$ fluorescence methods, ${ }^{(9-14)}$ and synchronous-derivative phosphorimetric determination. ${ }^{(15)}$ These methods have their own characteristics: some of them require expensive instruments and complicated sample processing, and they are not convenient to use in real-time field testing. Therefore, a rapid and accurate determination of 1-naphthol concentration is of practical significance. At present, the field environment real-time detection, mobile laboratory, portable detection instruments, and so on have a good prospect of development. The electrochemical method with simple and rapid features is gradually widely used. Therefore, in this study,

*Corresponding author: e-mail: wyc0104@126.com https://doi.org/10.18494/SAM.2020.2872 
we aim to establish a rapid and simple electrochemical method for the determination of 1-naphthol. $\beta$-cyclodextrin $(\beta-C D)$ is a functional supramolecule with a hydrophobic interior and a hydrophilic exterior, and may selectively recognize some organic or inorganic small molecules through nonbonding intermolecular forces. ${ }^{(16)}$ 1-Naphthol molecules entering into the cavity of $\beta-C D$ tend to accumulate on one side, which enhances the nonbonding forces between 1-naphthol and $\beta-\mathrm{CD}$, resulting in an enhancement of the electrochemical response of 1-naphthol on a glassy carbon electrode modified with poly $\beta$-CD film ( $\beta$-CD/GCE). In addition, $\beta-\mathrm{CD}$, which has a special cylindrical structure with external hydrophilic and internal hydrophobic chambers, can be combined with 1-naphthol to form the host- and guest-containing compounds. Therefore, it can be applied to the detection of 1-naphthol. In a preliminary work, we carried out extensive research on polymer electrodes, such as an electrode modified with a Prussian blue analog doped with copper (II) ions ${ }^{(17,18)}$ and a poly(methyl red)-modified electrode. ${ }^{(19)}$ We have also conducted some research on $\beta$-CD-film-modified electrodes by electrochemical polymerization. ${ }^{(20)}$ Using the results of previous work, we developed a new test system using the $\beta-\mathrm{CD} / \mathrm{GCE}$ prepared by electrochemical polymerization, which has made the rapid and accurate determination of the concentration of 1-naphthol a reality. Moreover, linear calibration ranges are wider and the detection limit is higher than literature values. ${ }^{(21,22)}$

\section{Materials and Methods}

\subsection{Apparatus and reagents}

All the electrochemical measurements were carried out on a CHI660C electrochemical workstation (Chenhua Instrument Co., Ltd., Shanghai, P. R. China). The KQ-400DB numerical control ultrasonic wave launder was purchased from Ultrasonic Instrument Co., Ltd. (Kunshan, P. R. China). A saturated calomel electrode (SCE), a platinum electrode, a glassy carbon electrode (GCE) of $4 \mathrm{~mm}$ diameter, a $\mathrm{pH}$ meter (PHS-3C, Shanghai Dapu Instrument Co., Ltd.), and the BS110S electronic balance (Shanghai Jingsheng Scientific Instrument Co., Ltd.) were also used. $\beta-\mathrm{CD}$, 1-naphthol, $\mathrm{K}_{3}\left[\mathrm{Fe}(\mathrm{CN})_{6}\right]$, concentrated $\mathrm{H}_{2} \mathrm{SO}_{4}$, concentrated $\mathrm{HNO}_{3}$, $\mathrm{KCl}, \mathrm{NaOH}, \mathrm{KH}_{2} \mathrm{PO}_{4}, \mathrm{~K}_{2} \mathrm{HPO}_{4}, \mathrm{HAc}$, and $\mathrm{NH}_{4} \mathrm{Ac}$ reagents were of analytical grade and used without further purification.

\subsection{Preparation of $\beta-\mathrm{CD} / \mathrm{GCE}$ electrode}

The GCE $(\Phi=4 \mathrm{~mm})$ was polished with emery paper, then washed ultrasonically for $3 \mathrm{~min}$ each in 1:1 NaOH solution, 1:1 $\mathrm{HNO}_{3}$ solution, pure alcohol, and distilled water, successively. The cleaned GCE was put in a $0.5 \mathrm{~mol} \cdot \mathrm{L}^{-1}$ solution of sulfuric acid, then cyclic voltammetry (CV) experiments were carried out in a potential range from -1.0 to $1.0 \mathrm{~V}$ with a scan rate of $0.10 \mathrm{~V} / \mathrm{s}$ until the peak current became stable, thus attaining an activation electrode. Next, the activation electrode was put in a saturated solution of $\beta-C D$ containing $0.1 \mathrm{~mol} \cdot \mathrm{L}^{-1}$ potassium chloride and $0.01 \mathrm{~mol} \cdot \mathrm{L}^{-1}$ sodium hydroxide for cyclic voltammetric experiments in a potential range from -1.0 to $1.0 \mathrm{~V}$ with a scan rate of $0.05 \mathrm{~V} / \mathrm{s}$ until the peak current became stable. The working 
electrode was taken out, rinsed, and then dried in air. A baby-blue film was observed on the surface of the working electrode, indicating the successful preparation of a steady $\beta-\mathrm{CD} / \mathrm{GCE}$.

\subsection{Analytical procedure}

A conventional three-electrode system, including a $\beta-\mathrm{CD} / \mathrm{GCE}$ or glassy carbon working electrode, a platinum-wire counter electrode, and a reference SCE, was employed using the CHI660C electrochemical workstation. Impedance from $0.1 \mathrm{MHz}$ down to $1 \mathrm{~Hz}$ was measured. The amplitude of the sinusoidal voltage was chosen to be $5 \mathrm{mV}$. Cyclic voltammograms were recorded from -0.8 to $0.9 \mathrm{~V}$ under various conditions, for example, scan rate, electrolyte, and 1-naphthol concentration. All the experiments were carried out at room temperature, and nitrogen was bubbled into the sample to remove the oxygen.

\section{Results and Discussion}

\subsection{Characterization of $\beta-C D / G C E$ electrode}

In $1.01 \times 10^{-3} \mathrm{~mol} \cdot \mathrm{L}^{-1}$ potassium ferricyanide solution containing $0.1 \mathrm{~mol} \cdot \mathrm{L}^{-1}$ potassium chloride, the $\beta-\mathrm{CD} / \mathrm{GCE}$ and activation electrode were used as the working electrodes and the cyclic voltammograms were recorded from -0.8 to $0.9 \mathrm{~V}$ with a scan rate of $0.10 \mathrm{~V} / \mathrm{s}$. The obtained results are presented in Fig. 1. Compared with the CV response on a bare GCE, a large well-defined peak appears on the $\beta-\mathrm{CD} / \mathrm{GCE}$. The peak potentials are 0.015 and $0.268 \mathrm{~V}$. These results indicate that the $\beta-\mathrm{CD} / \mathrm{GCE}$ shows good electrocatalytic action for potassium ferricyanide, but a bare GCE does not. The polymerized $\beta-\mathrm{CD} / \mathrm{GCE}$ was successfully prepared by electrochemical polymerization, and the electrocatalytic property of this modified GCE showed a significant change.

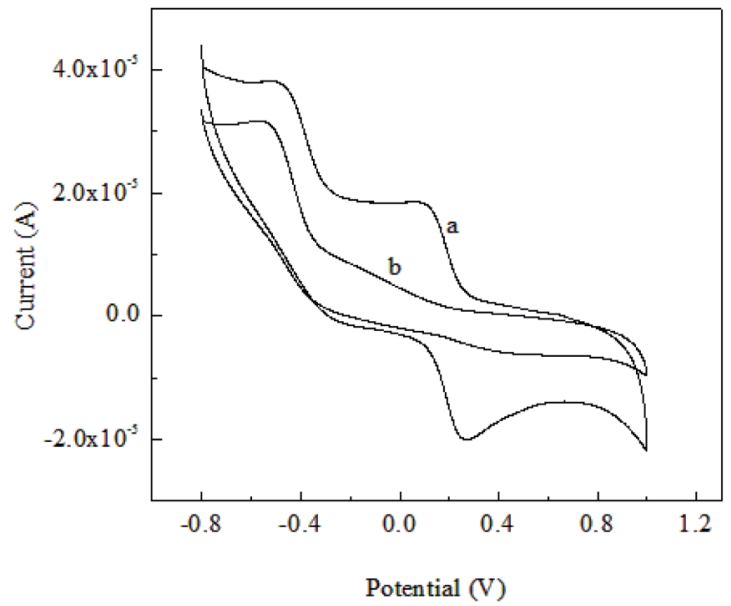

Fig. 1. Cyclic voltammograms for (a) $\beta-\mathrm{CD} / \mathrm{GCE}$ and (b) $\mathrm{GCE}$ in $\mathrm{K}_{3}\left[\mathrm{Fe}(\mathrm{CN})_{6}\right]$ solution. 
Typical complex impedance plots for the $\beta-\mathrm{CD} / \mathrm{GCE}$ and GCE in the $1.01 \times 10^{-3} \mathrm{~mol} \cdot \mathrm{L}^{-1}$ potassium ferricyanide solution containing $0.1 \mathrm{~mol} \cdot \mathrm{L}^{-1}$ potassium chloride are shown in Fig. 2. There is a high-frequency semicircle on the GCE and a quarter-circle on the $\beta-\mathrm{CD} / \mathrm{GCE}$. These results show that poly-( $\beta-C D)$ was successfully modified on the GCE by electrochemical polymerization, resulting in a clear change in impedance. By combining Figs. 1 and 2, we can see that the peak current of potassium ferricyanide is low for a bare GCE, and the corresponding impedance is larger. However, for the $\beta-\mathrm{CD} / \mathrm{GCE}$, the peak current of potassium ferricyanide markedly increases and its impedance decreases. These results show that the poly-( $\beta-C D)$ participates in the electron transfer process on the electrode surface and enhances the electron conductivity.

\subsection{Electrochemical behavior of 1-naphthol on $\beta$-CD/GCE}

Figure 3 shows the cyclic voltammograms of $1.03 \times 10^{-3} \mathrm{~mol} \cdot \mathrm{L}^{-1}$ 1-naphthol solution (curves $a$ and $c$ ) and the blank solution (curves $b$ and $d$ ) on the $\beta-\mathrm{CD} / \mathrm{GCE}$ (curves $a$ and $b$ ) and the bare

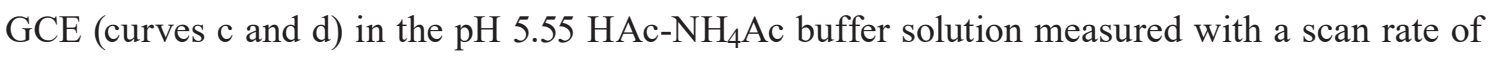
$0.12 \mathrm{~V} / \mathrm{s}$. In the blank solution, there is no clear peak current on either the $\beta-\mathrm{CD} / \mathrm{GCE}$ or the bare GCE. In the $1.03 \times 10^{-3} \mathrm{~mol} \cdot \mathrm{L}^{-1}$ 1-naphthol solution, the $\mathrm{CV}$ response of 1-naphthol on the $\beta-\mathrm{CD} / \mathrm{GCE}$ exhibits a large well-defined oxidation peak whose peak current is $-1.871 \times 10^{-5} \mathrm{~A}$. Compared with the 1-naphthol peak current of $-4.779 \times 10^{-6}$ A for the bare GCE, the peak current has almost quadrupled. This indicates that the electrochemical polymerization of $\beta$-CD on the GCE greatly improved the electrochemical reactivity of 1-naphthol and markedly enhanced the electrochemical response of 1-naphthol on the $\beta-\mathrm{CD} / \mathrm{GCE}$.

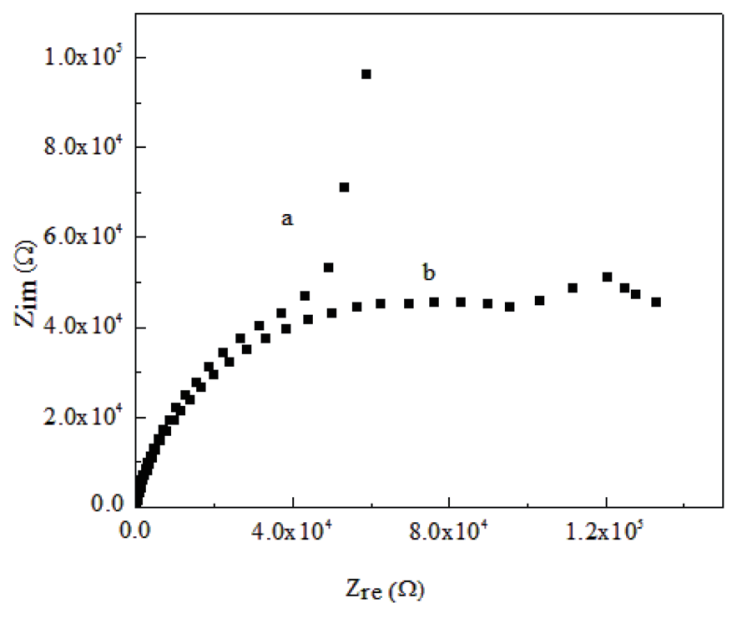

Fig. 2. Impedance plane plots for potassium ferricyanide on (a) $\beta-\mathrm{CD} / \mathrm{GCE}$ and (b) GCE.

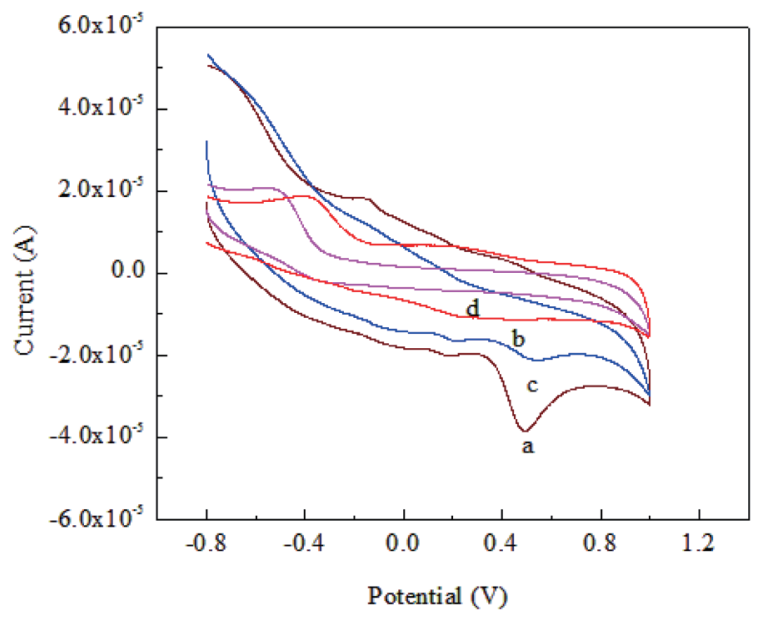

Fig. 3. (Color online) Cyclic voltammograms of $\beta-\mathrm{CD} / \mathrm{GCE}(\mathrm{a}, \mathrm{b})$ and GCE $(\mathrm{c}, \mathrm{d})$ in the HAc-NH $\mathrm{H}_{4} \mathrm{Ac}$ solution with $1.03 \times 10^{-3} \mathrm{~mol} \cdot \mathrm{L}^{-1}$ 1-naphthol $(\mathrm{a}, \mathrm{c})$ and the blank solution $(b, d)$. 


\subsection{Optimization of determination conditions}

\subsubsection{Effect of solution $\mathrm{pH}$}

With a scan rate of $0.12 \mathrm{~V} / \mathrm{s}$, we carried out $\mathrm{CV}$ analysis on the $\beta-\mathrm{CD} / \mathrm{GCE}$ in the HAc$\mathrm{NH}_{4} \mathrm{Ac}$ buffer solution with $1.03 \times 10^{-3} \mathrm{~mol} \cdot \mathrm{L}^{-1} 1$-naphthol at different $\mathrm{pH}$ values of 4.00, 5.55, 7.50, 8.52, and 10.03. The cyclic voltammograms are presented in Fig. 4. The plot of Ep vs pH is shown in the inset of Fig. 4. A marked electrocatalytic action of 1-naphthol on the $\beta$-CD/GCE is observed in the electrolyte at any $\mathrm{pH}$. Ep and Ip are affected by the $\mathrm{pH}$ of the electrolyte. When the $\mathrm{pH}$ is 4.00 , the peak shape is imperfect and the peak current is low, preventing the quantitative analysis of 1-naphthol. When the $\mathrm{pH}$ is above 8.52, 1-naphthol decomposes, resulting in a large measurement error. Ip is maximal and the electrocatalytic action is the most marked when the HAc- $\mathrm{NH}_{4} \mathrm{Ac}$ buffer solution of $\mathrm{pH} 5.55$ is used in the $\mathrm{CV}$ analysis. The $\mathrm{pH}$ dependence of $E p$ obeys the equation $E p=-0.06128 \mathrm{pH}+0.86273(R=0.9985)$. The slope of $61.28 \mathrm{mV} / \mathrm{pH}$ shows that equal numbers of protons and electrons were involved in the oxidation of 1-naphthol. ${ }^{(23)}$

\subsubsection{Effect of scan rate}

Figure 5 shows the plot of Ip and scan rate, and the cyclic voltammograms of $1.03 \times 10^{-3} \mathrm{~mol} \cdot \mathrm{L}^{-1} 1$-naphthol on the $\beta$-CD/GCE in HAc-NH $4 \mathrm{Ac}$ buffer solution of $\mathrm{pH} 5.55$ with different scan rates $(0.05,0.10,0.15,0.20,0.25$, and $0.30 \mathrm{~V} / \mathrm{s})$ are also shown in the inset. It is found from Fig. 5 that the oxidation peak current of 1-naphthol increased with the scan rate, which obeys the linear equation Ip (A) $=-7.714 \times 10^{-5} v\left(\mathrm{~V} \mathrm{~s}^{-1}\right)+4.257 \times 10^{-7}, R=-0.9931$.

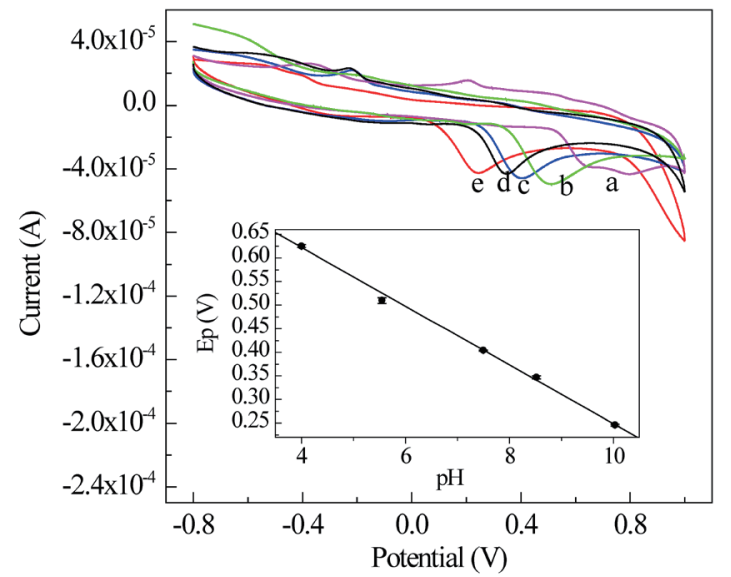

Fig. 4. (Color online) Cyclic voltammograms of $1.03 \times 10^{-3} \mathrm{~mol} \cdot \mathrm{L}^{-1} 1$-naphthol on the $\beta$-CD/GCE in HAc- $\mathrm{NH}_{4} \mathrm{Ac}$ buffer solution with various $\mathrm{pH}$ values: (a) 4.00 , (b) 5.55 , (c) 7.50, (d) 8.52, and (e) 10.03 . The inset shows the plot of $E p$ vs $\mathrm{pH}$.

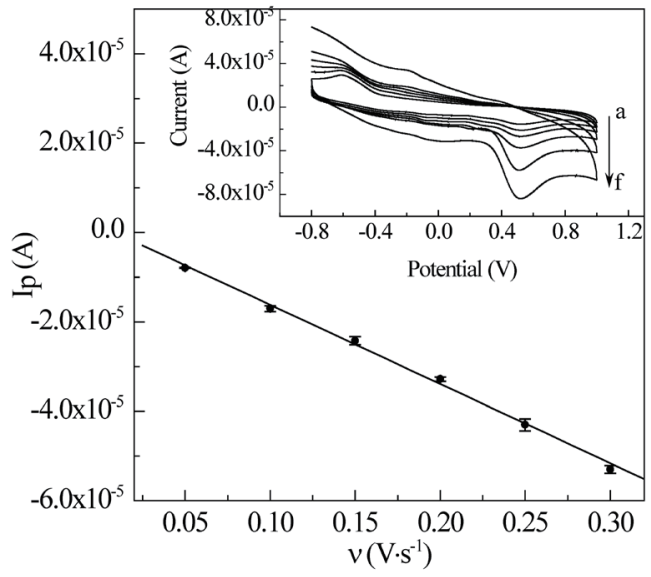

Fig. 5. Relationship between peak current and scan rate. The inset shows cyclic voltammograms of $1.03 \times 10^{-3} \mathrm{~mol} \cdot \mathrm{L}^{-1}$ 1-naphthol on $\beta$-CD/GCE in HAc- $\mathrm{NH}_{4}$ Ac buffer solution of $\mathrm{pH} 5.55$ with different scan rates: (a) 0.05 , (b) 0.10 , (c) 0.15 , (d) 0.20 , (e) 0.25 , and (f) $0.30 \mathrm{~V} \mathrm{~s}^{-1}$. 
This result shows that the electrocatalytic process was an irreversible process controlled by adsorption. When the scan rate reached $0.30 \mathrm{~V} / \mathrm{s}$, the peak shape changed and the background current became higher, which was not suitable for the determination of peak current. Therefore, the scan rate of $0.25 \mathrm{~V} / \mathrm{s}$ was used in the $\mathrm{CV}$ analysis.

\subsection{Linear relationship and detection limit, reproducibility, and stability}

Figure 6 shows the plot of Ip and 1-naphthol concentration, and the inset shows the cyclic voltammograms of 1-naphthol on the $\beta-\mathrm{CD} / \mathrm{GCE}$ in $\mathrm{HAc}-\mathrm{NH}_{4} \mathrm{Ac}$ buffer solution in the concentration range of $2.05 \times 10^{-3}-1.03 \times 10^{-6} \mathrm{~mol} \cdot \mathrm{L}^{-1}$. The linearity equation was defined as $I p(\mathrm{~A})=-0.0143 \mathrm{c}\left(\mathrm{mol} \cdot \mathrm{L}^{-1}\right)-4.347 \times 10^{-6}, R=0.9979$, and the detection limit was $3.06 \times 10^{-7} \mathrm{~mol} \cdot \mathrm{L}^{-1}$.

Under optimized test conditions, the cyclic voltammograms of $1.03 \times 10^{-3} \mathrm{~mol} \cdot \mathrm{L}^{-1}$ 1-naphthol on the $\beta-\mathrm{CD} / \mathrm{GCE}$ were recorded every day for a week. After testing, the $\beta-\mathrm{CD} / \mathrm{GCE}$ was rinsed and preserved in $\mathrm{HAc}-\mathrm{NH}_{4} \mathrm{Ac}$ buffer solution of $\mathrm{pH}$ 5.55. Three weeks later, the peak current remained roughly stable, indicating that the $\beta-\mathrm{CD} / \mathrm{GCE}$ has good stability. The results are shown in Table 1. Under the same experimental conditions, a relative standard deviation of $1.35 \%$ was obtained for ten repetitions of measuring $1.03 \times 10^{-3} \mathrm{~mol} \cdot \mathrm{L}^{-1} 1$-naphthol on the $\beta-\mathrm{CD} / \mathrm{GCE}$. Therefore, the $\beta-\mathrm{CD} / \mathrm{GCE}$ also has good reproducibility.

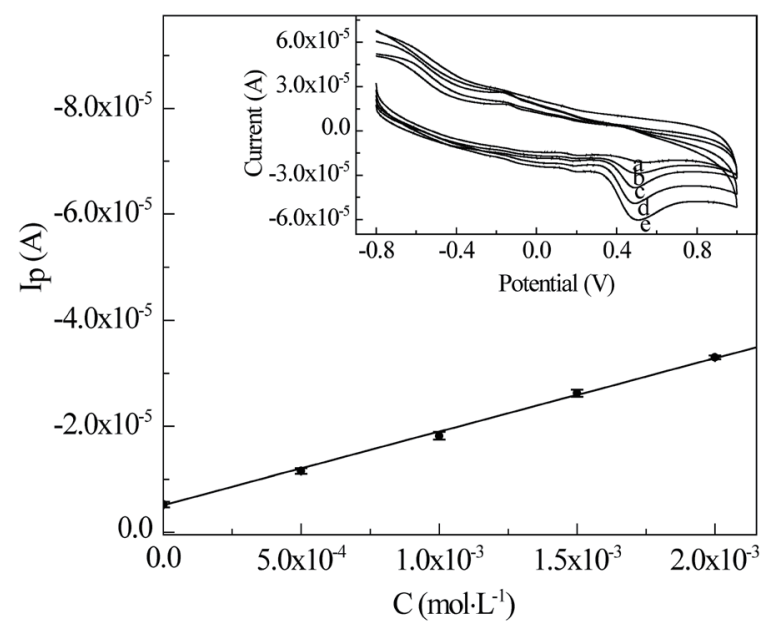

Fig. 6. Relationship between peak current and 1-naphthol concentration. The inset shows cyclic voltammograms for different 1-naphthol concentrations: (a) $1.03 \times 10^{-6}$, (b) $5.1 \times 10^{-4}$, (c) $1.03 \times 10^{-3}$, (d) $1.52 \times 10^{-3}$, and (e) $2.05 \times$ $10^{-3} \mathrm{~mol} \cdot \mathrm{L}^{-1}$.

Table 1

Results of long time stability.

\begin{tabular}{lcccccccc}
\hline Days & 1 & 2 & 3 & 4 & 5 & 6 & 7 & 21 \\
\hline$I_{P}\left(\times 10^{-5} \mathrm{~A}\right)$ & -1.815 & -1.822 & -1.815 & -1.811 & -1.816 & -1.813 & -1.801 & -1.779 \\
\hline
\end{tabular}




\subsection{Interference study}

Under the same experimental conditions as above and within the error allowed, the factors affecting the determination of $1.03 \times 10^{-3} \mathrm{~mol} \cdot \mathrm{L}^{-1} 1$-naphthol were studied. The results indicate that the 500-fold higher concentrations of $\mathrm{Al}^{3+}, \mathrm{Zn}^{2+}, \mathrm{Ca}^{2+}, \mathrm{Mg}^{2+}, \mathrm{SO}_{4}{ }^{2-}, \mathrm{CO}_{3}{ }^{2-}, \mathrm{NO}_{3}{ }^{-}, \mathrm{NH}_{4}{ }^{+}$, and $\mathrm{Na}^{+}$, the 100-fold higher concentrations of p-nitrophenol and p-aminophenol, and the 10-fold higher concentrations of hydroquinone, pyrocatechol, phenol, and bisphenol A did not affect the determination of 1-naphthol. However, a 50-fold higher concentration of 2-naphthol interfered with the determination. The results are shown in Table 2.

\section{Standard Addition Analysis of Samples}

A standard solution of $1.52 \times 10^{-3} \mathrm{~mol} \cdot \mathrm{L}^{-1}$ 1-naphthol was prepared in $\mathrm{pH} 5.55 \mathrm{HAc}-\mathrm{NH}_{4} \mathrm{Ac}$ buffer solution. Then, three samples were obtained by transferring $2.5,5.0$, and $10.0 \mathrm{~mL}$ of $1.52 \times 10^{-3} \mathrm{~mol} \cdot \mathrm{L}^{-1} 1$-naphthol standard solution to a $50 \mathrm{~mL}$ volumetric flask, diluting with $\mathrm{pH} 5.55$ HAc-NH 4 Ac buffer solution to make $50 \mathrm{~mL}$ volume, and mixing. The samples were labeled from 1 to 3, respectively. The standard addition analysis of the samples was carried out by CV with scanning from -0.8 to $0.9 \mathrm{~V}$ at a scan rate of $0.12 \mathrm{~V} \mathrm{~s}^{-1}$. The recovery rate was from 97.3 to $103 \%$. The results are shown in Table 3 .

Table 2

Interference study.

\begin{tabular}{lcc}
\hline Interfering ions & Concentration & Peak current $\left(\times 10^{-5} \mathrm{~A}\right)$ \\
\hline Nothing & - & -1.815 \\
$\mathrm{Al}^{3+}$ & $500 \mathrm{C}_{0}$ & -1.817 \\
$\mathrm{Zn}^{2+}$ & $500 \mathrm{C}_{0}$ & -1.816 \\
$\mathrm{Ca}^{2+}$ & $500 \mathrm{C}_{0}$ & -1.815 \\
$\mathrm{Mg}^{2+}$ & $500 \mathrm{C}_{0}$ & -1.812 \\
$\mathrm{SO}_{4}{ }^{2-}$ & $500 \mathrm{C}_{0}$ & -1.813 \\
$\mathrm{CO}_{3}{ }^{2-}$ & $500 \mathrm{C}_{0}$ & -1.817 \\
$\mathrm{NO}_{3}{ }^{-}$ & $500 \mathrm{C}_{0}$ & -1.818 \\
$\mathrm{NH}_{4}{ }^{+}$ & $500 \mathrm{C}_{0}$ & -1.810 \\
$\mathrm{Na}^{+}$ & $500 \mathrm{C}_{0}$ & -1.814 \\
p-nitrophenol & $100 \mathrm{C}_{0}$ & -1.815 \\
p-aminophenol & $100 \mathrm{C}_{0}$ & -1.817 \\
hydroquinone & $10 \mathrm{C}_{0}$ & -1.813 \\
pyrocatechol & $10 \mathrm{C}_{0}$ & -1.813 \\
phenol & $10 \mathrm{C}_{0}$ & -1.811 \\
Bisphenol A & $10 \mathrm{C}_{0}$ & -1.815 \\
2-naphthol & $50 \mathrm{C}_{0}$ & - \\
\hline
\end{tabular}

Table 3

Results of standard addition analysis and recovery test.

\begin{tabular}{lcccc}
\hline Sample & Original $\left(\mathrm{mol} \cdot \mathrm{L}^{-1}\right)$ & Added $\left(\mathrm{mol} \cdot \mathrm{L}^{-1}\right)$ & Measured $\left(\mathrm{mol} \cdot \mathrm{L}^{-1}\right)$ & Recovery $(\%)$ \\
\hline 1 & $7.50 \times 10^{-5}$ & $1.52 \times 10^{-4}$ & $2.25 \times 10^{-4}$ & 97.3 \\
2 & $1.52 \times 10^{-4}$ & $1.52 \times 10^{-4}$ & $3.09 \times 10^{-4}$ & 103 \\
3 & $3.02 \times 10^{-4}$ & $1.52 \times 10^{-4}$ & $4.49 \times 10^{-4}$ & 98.3 \\
\hline
\end{tabular}




\section{Conclusions}

A GCE modified with a poly $\beta$-CD film was prepared by electrochemical polymerization. The sensor was developed for use in a new test system for the measurement of the 1-naphthol concentration. The peak current of CV increased linearly with the 1-naphthol concentration in the range of $2.05 \times 10^{-3}-1.07 \times 10^{-6} \mathrm{~mol} \cdot \mathrm{L}^{-1}$, and its detection limit was $3.06 \times 10^{-7} \mathrm{~mol} \cdot \mathrm{L}^{-1}$ (3SNR). This method may also hold promise for potential applications in environmental analysis and measurement.

\section{Acknowledgments}

The authors are grateful for the financial support from the Open Foundation of Key Lab of Process Analysis and Control of Sichuan Universities (Yibin University Grant No. 2015003 and 2019004), the Doctor Research Fund of Yuncheng University (YQ-2019024), Applied Basic Research Programs of Foundation of Yuncheng University (CY-2019032), and the Subject Research Project of Foundation of Yuncheng University (XK-2019018 and XK-2019054).

\section{References}

1 Q. Zhou, M. Lei, J. Li, K. Zhao, and Y. Liu: J. Chromatogr. A. 1441 (2016) 1. http://www.sciencedirect.com/ science/article/pii/S0021967316302060

2 X. Yan, X. Hu, T. Chen, S. Zhang, and M. Zhou: J. Phys. Chem. Solids. 107 (2017) 50. https://doi.org/10.1016/ j.jpcs.2017.03.024

3 W. Chen, J. Dong, S. Zhou, C. Zhang, and D. Fu: J. Electroanal. Chem. 850 (2019) 113399. https://doi. org/10.1016/j.jelechem.2019.113399

4 R. Preuss and J. Angerer: J. Chromatogr. B. 801 (2004) 307. https://doi.org/10.1016/j.jchromb.2003.11.032

5 E. Elovaara, J. Mikkola, M. Mäkelä, B. Paldanius, and E. Priha: Toxicol. Lett. 162 (2006) 158. https://doi. org/10.1016/j.toxlet.2005.09.028

6 Q. Zhao, G. Li, Y. Ning, T. Zhou, Y. Mei, Z. Guo, and Y. Feng: Microchem. J. 147 (2019) 67. https://doi. org/10.1016/j.microc.2019.03.009

7 Y. Yuan, X. Xiao, Y. Wang, J. Xue, G. Li, R. Kang, J. Zhang, and L. Shi: Sens. Actuators, B 145 (2010) 348. https://doi.org/10.1016/j.snb.2009.12.017

8 J. Penalva, R. Puchades, A. Maquieira, S. Gee, and B. D. Hammock: Biosens. Bioelectron. 15 (2000) 99. https://doi.org/10.1016/S0956-5663(00)00059-2

9 K. Massey, D. Van Engelen, and I. Warner: Talanta 42 (1995) 1457. https://doi.org/10.1016/0039-9140(95)01595-

10 H. Bagheri and S. Creaser: J. Chromatogr. A. 547 (1991) 345. https://doi.org/10.1016/S0021-9673(01)88658-1

11 F. Sanchez and C. Blanco: Talanta 37 (1990) 573. https://doi.org/10.1016/0039-9140(90)80198-O

12 R. Kang, Y. Wang, H. Yang, G. Li, X. Tan, J. Xue, J. Zhang, Y. Yuan, L. Shi, and X. Xiao: Anal. Chim. Acta. 658 (2010) 180. https://doi.org/10.1016/j.aca.2009.11.015

13 G. Jia, L. Li, J. Qiu, X. Wang, W. Zhu, Y. Sun, and Z. Zhou: Spectrochim. Acta, Part A. 67 (2007) 460. https:// doi.org/10.1016/j.saa.2006.08.003

14 F. Wang, S. Ren, H. Meng, and L. Gao: Chinese J. Anal. Chem. 39 (2011) 915. https://kns.cnki.net/KCMS/ detail/detail.aspx?dbcode $=$ CJFQ\&dbname $=$ CJFD2011\&filename $=$ FXHX201106035\&v $=$ Mjg4MDc0SD1ETXF ZOUdZWVI4ZVgxTHV4WVM3RGgxVDNxVHJXTTFGckNVUjdxZlpPZHBGQ3ZuVzdyTk16WERkckc=

15 M. Hernández López, M. Algarra González, and M. Isabel López Molina: Talanta 49 (1999) 679. https://doi. org/10.1016/S0039-9140(99)00067-3

16 S. Xu, X. Zhang, S. Duan, X. Xu, and C. Zhou: Chem. J. Chinese U. (2011) 2210. https://kns.cnki.net/KCM $\mathrm{S} /$ detail/detail.aspx ?dbcode $=\mathrm{CJFQ} \&$ dbname $=\mathrm{CJFD} 2011 \&$ filename $=\mathrm{GDXH} 201109035 \& \mathrm{v}=$ MDk1MDdTN0Ro MVQzcVRyV00xRnJDVVI3cWZaT2RwRkN2blY3ekJJaW5UWnJHNEg5RE1wbzlHWV1SOGVYMUx1eF= 
17 Z. Liu, Y. Wang, and Q. Gong: Chin. J. Anal. Chem. 38 (2010) 1040. https://kns.cnki.net/kcms/detail/detail. aspx $? \mathrm{dbcode}=\mathrm{CJFD} \& \mathrm{dbname}=\mathrm{CJFD} 2010 \&$ filename $=$ FXHX201007036\&v $=$ MjI2NDV4WVM3RGgx VDNxVHJXTTFGckNVUjdxZmJ1ZHBGeXpnVTd2TU16WERkckc0SDIITXFJOUdZb1I4ZVgxTHU=

18 Z. Liu, Y. Wang, Q. Gong, and H. Ma: J. Instrum. Anal. 29 (2010) 171. https://doi.org/10.3969/ j.issn.1004-4957.2010.02.014

19 Z. Liu, Y. Wang, Q. Gong, W. Zhang, and X. Liu: J. Shaanxi Univ. Techno: Nat. Sci. Ed. 27 (2011) 56. https:// doi.org/10.3969/j.issn.1673-2944.2011.04.012

20 Z. Liu, Q. Gong, Y. Wang, L. Meng, and S. Ma: J. Anal. Sci. 28 (2012) 543. https://kns.cnki.net/ $\mathrm{kcms} /$ detail/detail.aspx $? \mathrm{dbcode}=$ CJFD\&dbname $=$ CJF D2012\&filename $=$ FXKX201204024\&v =MTE3OTMzcVRyV00xRnJDVVI3cWZidWRwRn16Z1Y3M1BJelhBZHJHNEg5UE1xND1IWU1S OGVYMUxleFITNORoMVQ=

21 X. Wang, Q. Wu, Y. Ding, and Y. Fan: J. Tongji University (Natural Science) 02 (2008) 69. https://doi. org/10.3321/j.issn:0253-374X.2008.02.013

22 X. Wang, L. Tian, T. Dong, K. Wu, and Y. Hu: Phys. Test. Chem. Anal. (Part B: Chemical Analysis) 55 (2019) 266. https://kns.cnki.net/kcms/detail/detail. asp $x$ dbcode $=$ CJFD\&dbname $=$ CJFDLAST2019\& filename $=$ LHJH201903004\&v $=$ Mjc4NzBoMVQz cVRyV00xRnJDVVI3cWZidWRwRn16Z1ZicktLU1hCWnJHNEg5ak1yST1GWU1SOGVYMUx1eF1TN0Q=

23 J. Li, Y. Wang, and Z. Liu: Russ. J. Electrochem. 42 (2006) 27. https://doi.org/10.1134/S1023193506010058

\section{About the Authors}

Zhaorong Liu received his B.S. degree from Yanbei Normal College, China, in 2002 and his M.S. degree from China West Normal University, China, in 2005. From 2005 to 2007, he was an assistant at Yuncheng University, China. From 2008 to 2012, he was an instructor at Yuncheng University, China. Since 2013, he has been an associate professor at Yuncheng University. His research interests are in electrocatalysis and sensors. (1zr0104@163.com)

Yuchun Wang received her B.S. degree from Inner Mongolia Normal University, China, in 2003, M.S. degree from China West Normal University, China, in 2006, and Ph.D. degree from Taiyuan University of Technology, China, in 2016. From 2006 to 2008, she was an assistant at Yuncheng University, China. From 2009 to 2018, she was an instructor at Yuncheng University, China. Since 2019, she has been an associate professor at Yuncheng University. Her research interests are in heterogeneous catalysis, electrocatalysis, and sensors. (wyc0104@126.com)

Chao Tan received his B.S. degree from Southwest University of Science and Technology, China, in 1996, M.S. degree from the China West Normal University, China, in 2003, and Ph.D. degree from Sichuan University, China, in 2008. From 1996 to 1999, he successively worked as an LCD quality engineer at Taiwan Huatai Electronics and Japan Casio Electronics. From 2009 to 2010, he was an assistant at Yibin University, China. Since 2011, he has been a professor at Yibin University, China. His research interests are in analytical stoichiometry, biomedical analysis, and on-line spectral analysis. (453966144@qq.com) 
